\title{
Output Forms for Calculation Results in the Computing \& Geo-Information System
}

\author{
Ivan Trofimov \\ Melentiev Energy Systems Institute of Siberian Branch of \\ the Russian Academy of Sciences \\ Irkutsk, Russia \\ t_john88@isem.irk.ru \\ Leonid Trofimov \\ Melentiev Energy Systems Institute of Siberian Branch of \\ the Russian Academy of Sciences \\ Irkutsk, Russia \\ trofi.isem@yandex.ru
}

\author{
Lyudmila Chudinova \\ Melentiev Energy Systems Institute of Siberian Branch of \\ the Russian Academy of Sciences \\ Irkutsk, Russia \\ chudinova@isem.irk.ru \\ Sergei Podkovalnikov \\ Melentiev Energy Systems Institute of Siberian Branch of \\ the Russian Academy of Sciences \\ Irkutsk, Russia \\ spodkovalnikov@isem.irk.ru
}

\begin{abstract}
The paper discusses about special Computing and Geo-Information System with ObjectOriented Energy Database. The System is used to carries out the research of feasibility and prospects of Interstate Power Interconnection expansion. For this purpose, the mathematical model for Optimization of Power Systems Expansion and Operating Modes, which is the main part of the System, is used. An interface for working with the Model is developed. The output forms for calculation results by the Model in tabular, graphic and cartographic forms are presented.
\end{abstract}

Keywords- computing system, geo-information system, optimization model, data processing, object database, power plant, power system, interstate power interconnection

\section{INTRODUCTION}

We develop an object-oriented system for storing and processing energy and economic information with algorithms for verification, search and group data. Software tool for extracting arrays of information, with their subsequent processing and output of the results in the form of tables, graphs and charts on geographical maps have developed [1]:

- Special query designer to the object database have developed and continue to be improved.

- Algorithms for automating of the graphs creation are adapted to the data structure.

- The tool for construction and editing geographical maps has developed, with the ability to overlay layers containing energy and economic information in the form of numbers and charts.

On the other hand, authors have the Model for Optimization Power Systems Expansion and Operating Modes (called ORIRES) [2]. The Model is used to study different scenarios of Interstate Power Interconnection (IPI) expansion for prospective target year. In this Model, a linear optimization method is used to find a solution, which takes into account the minimum annualized costs, computing the optimal structure of various capacity types in each power system and their optimal operating modes at each hour of the day and in different seasons of the year.

We call the integrated Energy Database software and the Model as the Computing and Geo-Information System (CGIS). A huge amount of information obtained as a result of solving an optimization problem with tens of thousands of variables requires their understanding and interpretation. The use of CGIS tools, adapted to the specifics of the problem, allows one to do it. This article shows some aspects of tabular, graphical and cartographic representation of of the optimization problem in an easy-to-understand form.

The CGIS has intensively used for research of interstate power interconnections in Northeast Asian region.

The CGIS integrates both computing and informational components in one software product. The processing and analysis of huge amount of complex and rapidly growing data requires special software for data management and storage. We create and fill the special energy database (OODB). The database is based on the object-oriented file structure, Fig. 1.

The database objects contain geographical information for visual presentation and qualitative analysis; information on the relationships between objects, their regional affiliation; technical and economic parameters of objects and other information:

- Raster data - geo-data about countries and regions (tiles downloaded from google maps) are used as the background;

- Vector data - data in the SHP format, containing the geo-coordinates of power plants, country borders and administrative divisions;

- Energy parameter data - the technical and economic information about power plants, electric ties, energy power systems (EPS), etc. the results, which allow comparing various solutions

\section{ENERGY DATA STORAGE}




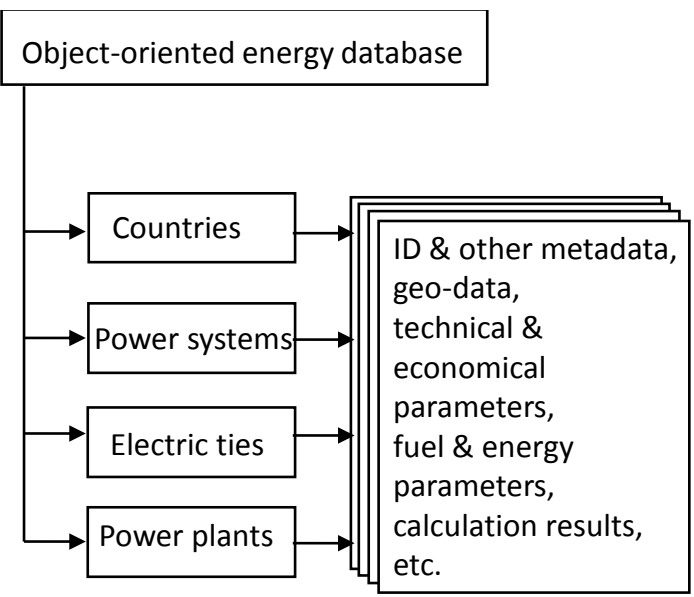

Fig. 1. Logical structure of the database

The data sources are global energy associations such as the International Energy Agency [3], British Petroleum; different energy databases and Internet resources; statistical tables in Excel; national outlooks and power balances. We use manual and semiautomatic processing algorithms for data load parsing of MS Excel and automatic downloading the entire data spreadsheets from various public energy databases. The certain algorithm for loading and converting the data depends on certain types of data sources.

Design of the OODB file structure and data access interface is unique and developed by the authors.

\section{SOFTWARE IMPLEMENTATION OF THE MODEL}

The CGIS is used to carries out the research of feasibility and prospects of Interstate Power Interconnection expansion for prospective target year. For this purpose, the mathematical model for Optimization of Power Systems Expansion and Operating Modes, which is the main part of the CGIS, is used. An interface for working with the Model is developed.

In this Model, a linear optimization method is used to find a solution, which determines the optimal installed capacity and generation type mix of the considered power systems and their interconnections, the intersystem and interstate electric ties transfer capabilities, and the operating modes of these capacities and ties. Each power system is represented in the Model by its own power generating capacities, both current and potential ones, aggregated by type of power plants. Consumers demand characterized by graph of daily electrical load, which determines how much electricity needs to generate for each hour (24 per day). The problem of determining the actual power for each type of power plants is considered in the modeled EPSs, taking into account the electricity transfer between these systems. The main result is a solution, which takes into account the minimum annualized costs, computing the optimal structure of various capacity types in each EPS and their optimal operating modes at each hour of the day and in different seasons of the year (winter / spring / summer / fall, weekdays / weekends).

The objective function of the Model consists of the total annualized fuel costs, annualized investment costs of new installed capacities (electricity generation type mix), and the annualized investment costs of new electric ties.

There are set of constraints: a) on expansion of power plants; b) on expansion of electric ties; c) on actual power of power plants for each 24 hours in the certain seasons and days; d) on power flows via electric ties; and other integral constraints on hydropower resources availability for hydro- and pumped storage power plants.

The CGIS uses the General Algebraic Modeling System (GAMS) for solving linear programming problem (LP-optimizer) that runs from the CGIS interface, reads the Model parameters and finds the optimal solution at the output spreadsheets [4].

We have developed algorithms for the interpretation of the mathematical Model equations in the programming language for GAMS. All equations and constrains are customized through the GAMS interface, that runs from the CGIS, Fig. 2.

The calculation results can be displayed in a graphical way by the geo-visualization technologies in the CGIS interface.

\section{DATA ANALYSIS IN THE GRAPHICAL AND TABULAR FORMS}

Our research is concerned with the construction and analysis of various scenarios of Interstate Power Interconnection expansion for the prospective target year, in the Northeast Asia region (NEA). This research is carried out in many international organizations, as it affects the interests of many Asian countries [5-8]. First, the main (base) scenario of NEA IPI expansion is computed with the initial values of the Model parameters set. All other scenarios are different variations of the main (parent) scenario, Fig. 3.

When forming an optimization problem, the input data for linear optimizer GAMS are taken from current scenario directory, and if it is empty - the data is automatically loaded from the parent scenario dir. In the main scenario, we consider and optimize Isolated Work of each Power System without any connections. In the next scenarios, we consider power systems collaboration with many options \& variants.

Many different forms are developed for viewing and analyzing the obtained results for each node of IPI scheme [9]. One of them is a graph with diagrams of the optimized installed capacity (computed by the Model) and initial conditions (constrains on the installed capacities). The graphical interface in the CGIS allows us to conduct a visual analysis of the results calculated by the Model, see Fig. 4 . 


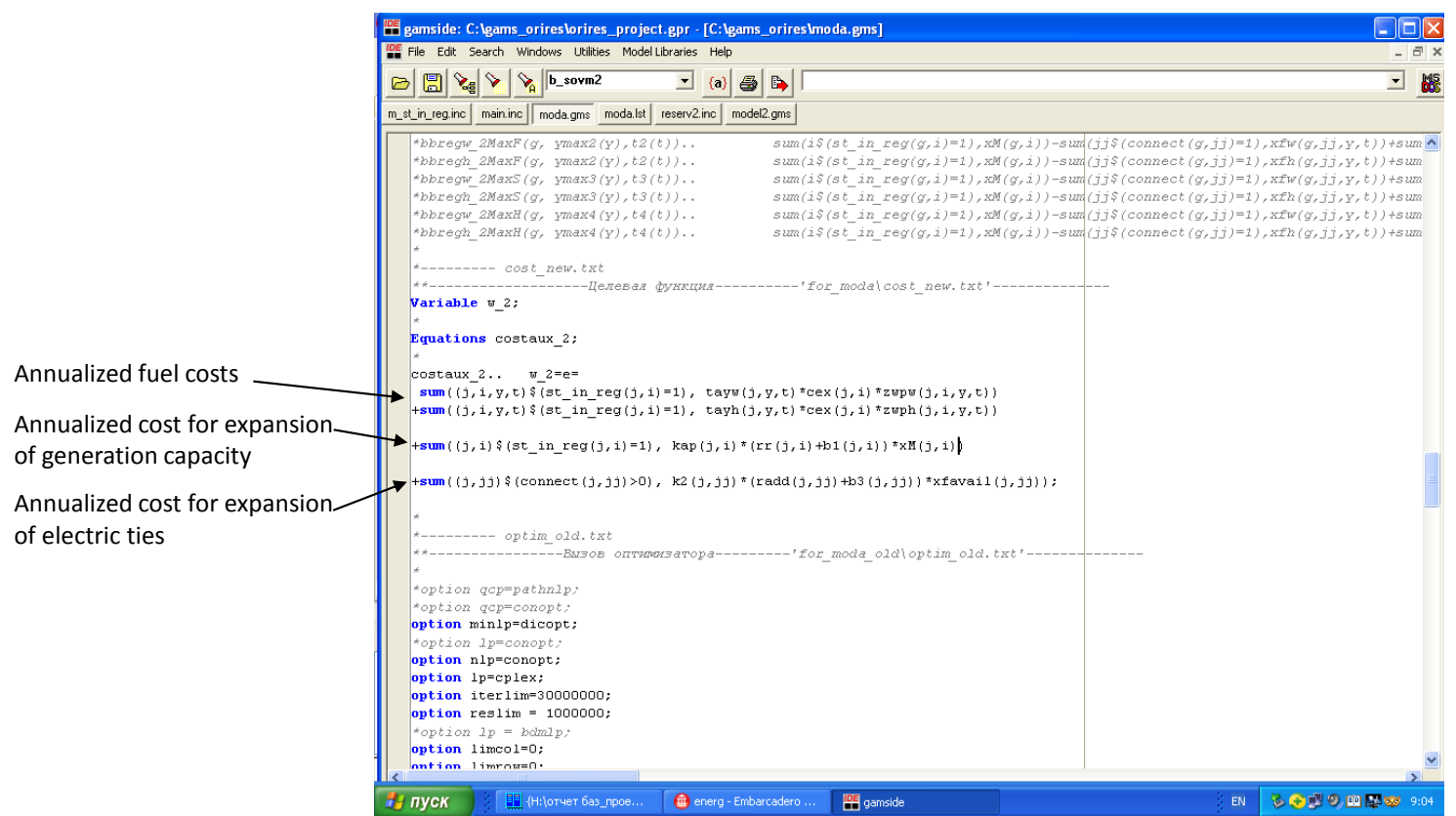

Fig. 2. The General Algebraic Modeling System Interface

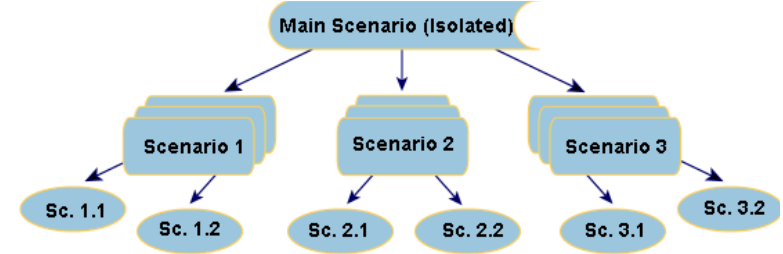

Fig. 3. Scenario tree, each subsequent scenario is the successor of the previous one computed earlier

The first column/diagram of figure 4 is the maximum possible capacity (generation type mix) in the node, which stands for the Center-China power system for the target year (2035). The second column is the optimized installed capacity, which is obtained by solving an optimization problem. The third column is the current installed capacity (for the target year). The second column (optimized installed capacity) is the main result of solving the optimization problem for each node of IPI scheme. Columns 4 and 5 - the limits of the actual (operating) power for each type of power plant (installed capacity), which depend on their technical characteristics.

On the right part of figure 4 is the graph of daily electrical load for the Center-China power system (2035). The diagrams under the daily load graph show how much power and what type of power plant is used for each hour (1-24).

Usually we consider eight different types of daily load graphs (summer, autumn, winter and spring on weekdays or holidays) for certain scenario. All

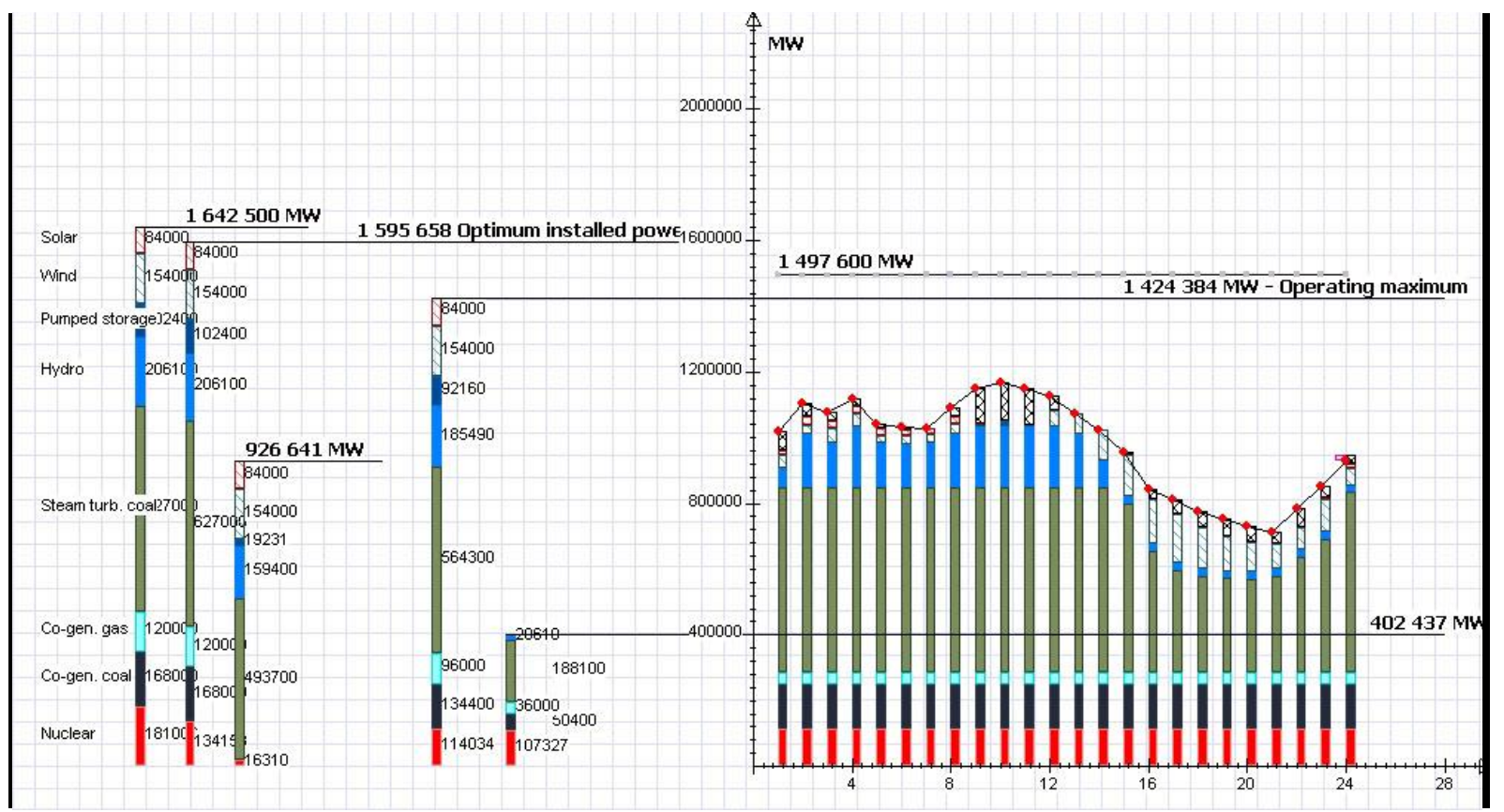

Fig. 4. Diagrams of the optimized installed capacity with initial conditions \& the graph of daily electrical load for the Northeast China power system $(2035$ 
information for each scenario is stored in the appropriate directory in the database.

The tabular forms allow us to analyze more detailed information. Automatic construction of the tables, graphs and charts significantly increase the efficiency of IPI expansion research. Table 1 presents the daily balance of generation and electricity transmission for the Center-China power system (2035).

TABLE I. THE DAILY BALANCE FOR CENTER-CHINA POWER SYSTEM (WINTER, WEEKEND), 2035

\begin{tabular}{|c|c|c|c|c|}
\hline Capacity type & $\begin{array}{c}\text { Max } \\
\text { installed } \\
\text { capacity, } \\
\boldsymbol{G W} \\
\end{array}$ & $\begin{array}{c}\text { Optimal } \\
\text { installed } \\
\text { capacity, } \\
\text { GW } \\
\end{array}$ & $\begin{array}{c}\text { Initial } \\
\text { installed } \\
\text { capacity, } \\
\boldsymbol{G W} \\
\end{array}$ & $\begin{array}{c}\text { Generat } \\
\text { ion, } \\
\boldsymbol{G W h}\end{array}$ \\
\hline Solar & 84 & 84 & 84 & 191 \\
\hline Wind & 154 & 154 & 154 & 1513 \\
\hline $\begin{array}{l}\text { Pumped } \\
\text { storage }\end{array}$ & 102 & 102 & 19.2 & 13.2 \\
\hline Hydro & 206 & 206 & 159 & 2284 \\
\hline $\begin{array}{c}\text { Steam turbine } \\
\text { coal }\end{array}$ & 627 & 627 & 494 & 11563 \\
\hline $\begin{array}{c}\text { Cogeneration } \\
\text { gas } \\
\end{array}$ & 120 & 120 & 0 & 864 \\
\hline $\begin{array}{c}\text { Cogeneration } \\
\text { coal }\end{array}$ & 168 & 168 & 0 & 3226 \\
\hline Nuclear & 181 & 134 & 16.3 & 2737 \\
\hline Subtotal & 1643 & 1596 & 927 & 22390 \\
\hline $\begin{array}{l}\text { Mongolia } \\
\text { import }\end{array}$ & 15 & 15 & 0 & 0.8 \\
\hline $\begin{array}{c}\text { Northeast } \\
\text { China import }\end{array}$ & 64 & 64 & 64 & 317 \\
\hline $\begin{array}{c}\text { Northwest } \\
\text { China import }\end{array}$ & 139 & 139 & 139 & 661 \\
\hline $\begin{array}{c}\text { Pumped } \\
\text { storage } \\
\text { (accumulation) }\end{array}$ & 0 & 0 & 0 & -16.5 \\
\hline Total load & 1643 & 1596 & 927 & 23351 \\
\hline
\end{tabular}

\section{THE GEOGRAPHICAL INTERFACE}

The geographical interface for CGIS is designed and implemented. The constructed maps include both geo-data and electrical parameters data [10]. As a background, we use raster geo-data. The map background is displayed by applying tiles, downloaded from google servers. The map tiles of different areas and scales are applied to the map background layer, Fig.5. All constructed maps are stored in the database.

On the next map layer, we use vector data from OODB - the data in the SHP (Shape) file format, containing the geo-coordinates of power plants, country borders and administrative divisions. There are geo-data about all countries and it subdivisions in the world. In addition, we have geo-coordinates of the biggest cities and power plants. Vector data is used for creating borders for power systems. On the Fig. 6 we can see Northern China \& North-East China power system borders.

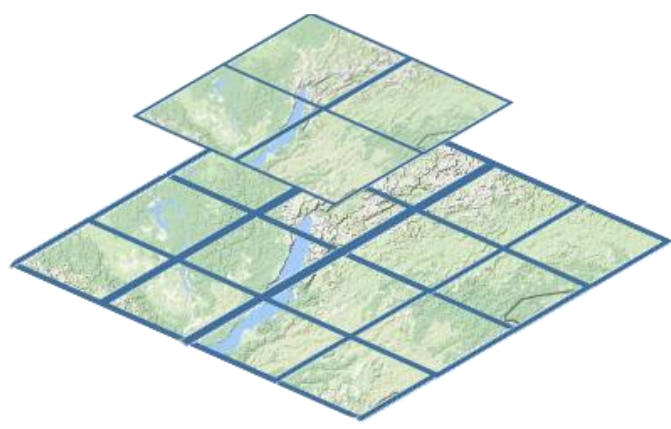

Fig. 5. Google tiles download on different scale

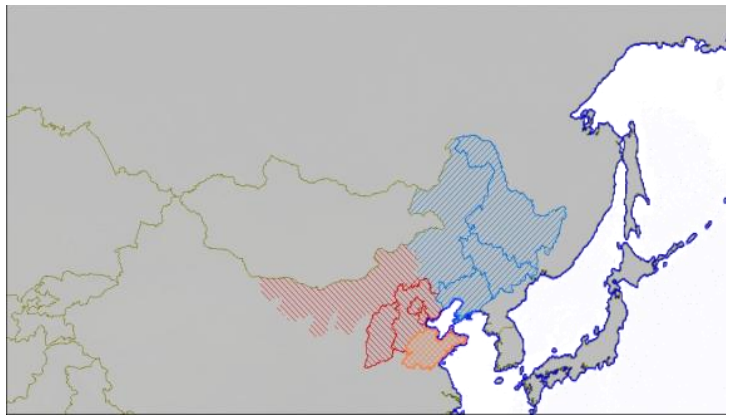

Fig. 6. Vector data on the map layer. The Northern China \& North-East China power system borders

Then we combine vector and raster data in the same map area, Fig. 7.

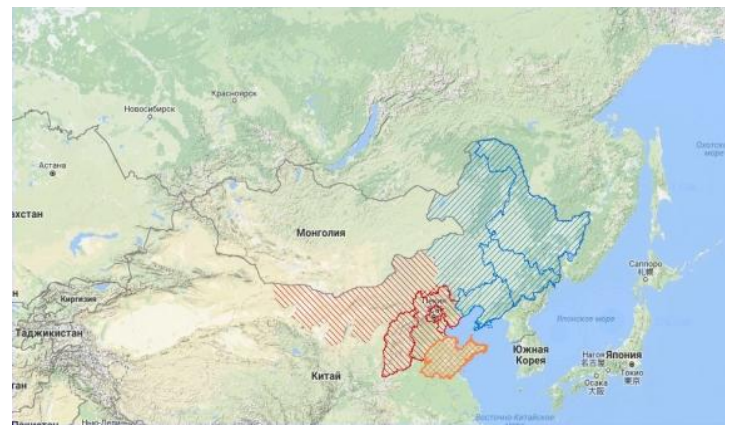

Fig. 7. Combined vector and raster data in the geographical interface

Finally, the energy data are drawn on the map, which is include the technical and economic information about power plants, electric ties, energy power systems, etc. The energy data are include both the input (initial) data and the obtained data computed by the Model. There are design scheme of Northeast Asia Power Grid with optimized installed capacities in each power system, assumed to be 2035, see Fig. 8 .

The nodes (EPSs) on the map are shown as pie charts. The centers of pie charts reflect the optimized installed capacity at each node $(G W)$. The shaded pie charts represent the total (annual) electricity generation in each node $(G W h)$. Optimized electric ties capability is plotted in the middle of each node-tonode link $(M W)$. The black small charts with straight lines between nodes indicate the direction of electricity flows between nodes per year $(G W h)$. 


\section{CONCLUSION}

The multi-aspect results of calculations by the Model are hardly perceived by experts without using of special software with the convenient user interface. The large amount of input and output data requires the creation of special forms that take into account the specifics of the Model, and which allow us to see the differences between scenarios, and effectively assess the quality of each solution. The specific output forms in the CGIS interface shown in this paper allow us to visually evaluate and analyze the obtained results of various scenarios of interstate power interconnection expansion. The creation of the scenario tree allows us to efficiently store and generate data for computational experiments.

Easy-to-understand forms allow us to see differences between different scenarios, and effectively assess the quality of each solution. The automatic construction of the tables, graphs and maps significantly increase the efficiency of interstate power interconnection expansion research.

\section{ACKNOWLEDGMENT}

The paper was done with a financial support from the Russian Foundation for Basic Research grant No. 18-07-00495-A.

\section{REFERENCES}

[1] I.L. Trofimov, L.N. Trofimov and S.V. Podkovalnikov, "Data Representation from Energy Balances by Using Geoinformation System", in Vth International workshop "Critical Infrastructures: Contingency Management, Intelligent, Agentbased, Cloud Computing and Cyber Security, IWCI 2018”, vol. 158, Advances in Intelligent Systems Research. Atlantis Press, 2018, pp. 177-182.

[2] L.S. Belyaev, L.Yu. Chudinova, O.V. Khamisov, G.F. Kovalev, L.M. Lebedeva, S.V. Podkovalnikov and V.A. Savel'ev, "Studies of interstate electric ties in Northeast Asia", vol. 17(3), International Journal of Global Energy Issues, 2002, pp. 228-249

[3] International Energy Agency: Data Services. (2016, February 24). Retrieved from http://wds.iea.org/WDS/Common/Login/login.aspx

[4] M.R. Bussieck, A. Meeraus, "General Algebraic Modeling System (GAMS)". Chapter 8. In: Kallrath J. (eds) Modeling Languages in Mathematical Optimization. Applied Optimization, vol. 88, Springer, Boston, MA, 2004.

[5] R. Omatsu, "Interim Report by Asia International Grid Connection Study Group" in 10th International Conference on Asian Energy Cooperation "AEC 2017", vol. 27, E3S Web of Conf, 2018, pp. 9-18.

[6] M. Seung, "Role of Korea for Developing the East Asia Super Grid" in 20th International Conference on Electrical Engineering, Jeju, 2014.

[7] J. Yoon, D. Park and H.Y. Kim, "The Pre-feasibility Results of NEAREST between the ROK, and the DRPK, and RF", in 6th Intern. conf. Asian Energy Cooperation: Forecast and Realities, Irkutsk, 2008, pp. 59-67.

[8] A. Tofael, S. Mekhilef, R. Shah, N. Mithulananthan, M. Seyedmahmoudian and B. Horan, "ASEAN power grid: A secure transmission infrastructure for clean and sustainable energy for South-East Asia, Renewable and Sustainable Energy Reviews", vol. 67, Elsevier, 2017, pp. 1420-1435.

[9] S.V. Podkovalnikov, I.L. Trofimov and L.N. Trofimov, "Data processing and optimization system to study prospective interstate power interconnections", in 10th International Conference on Asian Energy Cooperation, AEC 2017, vol. 27, E3S Web Conf., 2018, pp. 32-40.

[10] L. Xuming, "Application and research of global grid database design based on geographic information", vol. 1(1), Global Energy Interconnection Development and Cooperation Organization, 2018, pp. 87-95.

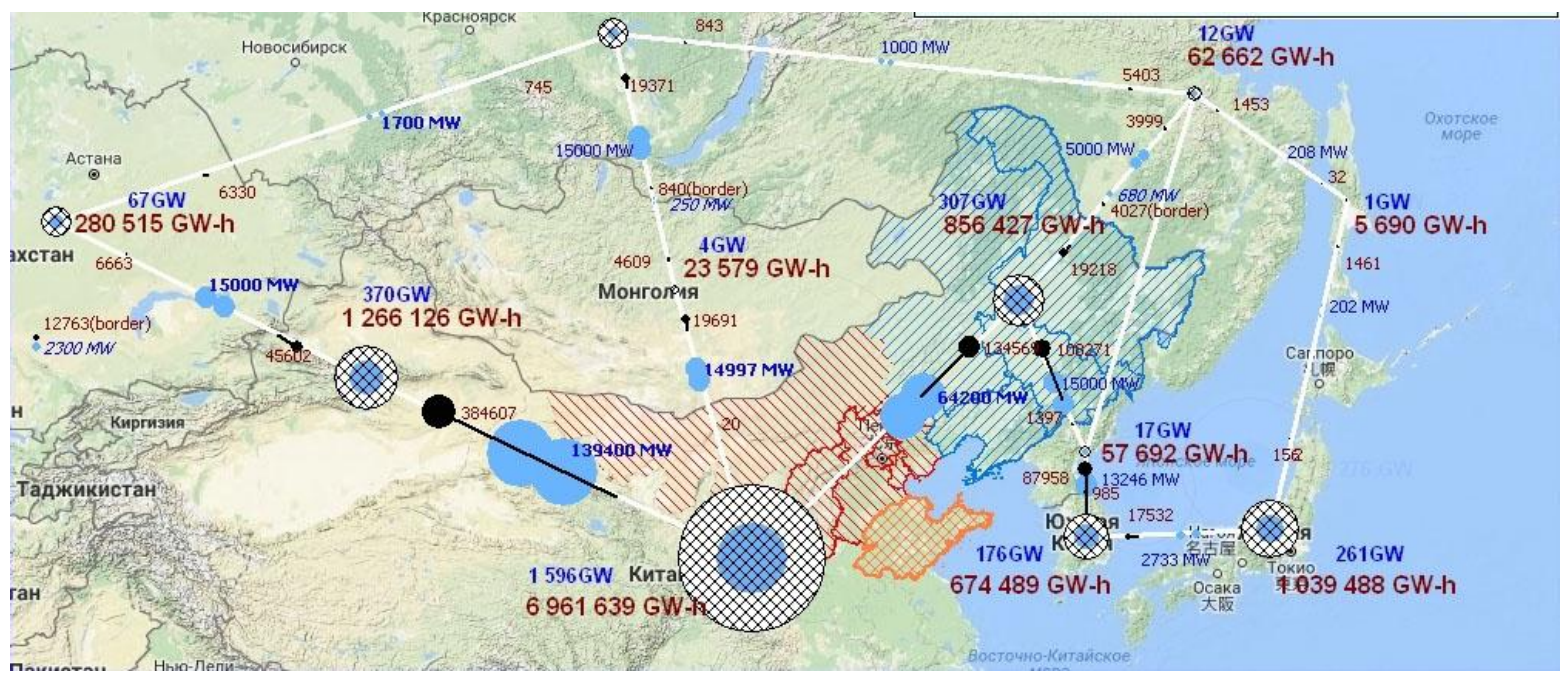

Fig. 8. The design scheme of Northeast Asia Power Grid (2035) 